\title{
Evidence of phenotypic correlation between exploration activity and resting metabolic rate among populations across an elevation gradient in a small rodent species
}

\author{
Mikko Lehto Hürlimann ${ }^{1}$ • Julien G. A. Martin ${ }^{2}$ - Pierre Bize ${ }^{1,2}$ (D) \\ Received: 17 April 2019 / Revised: 23 July 2019 / Accepted: 5 August 2019 / Published online: 28 August 2019 \\ (C) The Author(s) 2019
}

\begin{abstract}
Behavior and metabolism are frontline reactions to environmental challenges that can covary in their response through at least two mechanisms. First, natural selection can generate correlation in phenotype among distinct populations if they are exposed to a common selective force. Thus, metabolism and behavior can exhibit phenotypic correlation among populations when responding (independently from each other) to co-varying selective forces. Second, because behavioral responses are energy-demanding, variation in energy acquisition or allocation among individuals of the same population can also generate, respectively, a positive or negative correlation within populations. To address this issue, we investigated among- and within-population (co)variations in exploration activity (EA) and resting metabolic rate (RMR) of adult common voles (Microtus arvalis) issued from four highelevation populations (> $1400 \mathrm{~m}$ a.s.l.) and five low-elevation populations $(<520 \mathrm{~m}$ a.s.l.). Individuals were acclimatized for at least 1 month to the same laboratory conditions before being tested for EA and RMR. Voles from high-elevation populations were more explorative and they had higher RMR than their counterparts from low-elevation populations. The similar effects of elevation on EA and RMR accounted for a correlation of $0.28(0.064$; 0.658$)$ between EA and RMR across low- and highelevation populations. We found no evidence of a within-population correlation between EA and RMR. More work relying, for instance, on repeated sampling or experimental selection is nonetheless needed to confirm a lack of integration between metabolism and behavior at the individual level. Our results highlight the importance of co-varying selective forces in generating among-population phenotypic correlation between EA and RMR in this small rodent species.
\end{abstract}

\section{Significance statement}

There is increasing interest at deciphering the sources of covariation between metabolism and behavioral traits. Phenotypic covariation can be observed among populations if metabolism and behavior are responding independently from each other to covarying selective forces. Because behavioral responses are energy-demanding, variation in energy acquisition or allocation between individuals of the same population can also lead to, respectively, a positive or negative phenotypic correlation. In this study, we highlight the importance of co-varying selective forces in generating phenotypic correlation between metabolism and behavior across low- and high-elevation populations of a small rodent species. We found no evidence of a correlation within populations. More work relying, for instance, on repeated sampling or experimental selection is now needed to confirm a lack of integration between metabolism and behavior at the individual level.

Keywords Personality $\cdot$ Metabolism $\cdot$ Natural selection $\cdot$ Ecological gradient $\cdot$ Wild-derived mammals $\cdot$ Phenotypic covariation

Communicated by E. Korpimäki

Electronic supplementary material The online version of this article (https://doi.org/10.1007/s00265-019-2740-6) contains supplementary material, which is available to authorized users.

Pierre Bize

pierre.bize@abdn.ac.uk

1 Department of Ecology and Evolution, University of Lausanne, Lausanne, Switzerland
2 School of Biological Sciences, University of Aberdeen, Aberdeen, UK 


\section{Introduction}

Metabolism and behavior are frontline responses to environmental challenges, and their variations among species, or among populations of the same species, are expected to reflect adaptations to local environmental conditions (Réale et al. 2010; Piersma and van Gils 2011; Goulet et al. 2017). Until recently, variations in metabolism and behavior have been foremost the topic of separated fields of research (i.e., ecophysiology vs. behavioral ecology). The relevance of such separate approaches is currently challenged by a growing number of theoretical studies suggesting that metabolic and behavioral traits are likely to covary and emphasizing that the mechanisms generating such covariation remain however little investigated (Careau et al. 2008; Biro and Stamps 2010; Réale et al. 2010; Careau and Garland 2012; Mathot and Dingemanse 2015; Sih et al. 2015; Holtmann et al. 2017). At least two biological mechanisms can account for covariations between metabolism and behavior among populations and individuals of the same species.

Firstly, there is increasing evidence that natural selection can generate convergence in phenotype among distinct populations of the same species exposed to a common selective force. This can occur through recurrent recruitments of the same genetic changes (Christin et al. 2010; Hague et al. 2017), through recurrent phenotypic changes fostered by phenotypic plasticity (Dennis et al. 2011) or through a combination of those two processes (Conover and Schultz 1995; Oke et al. 2016). Because variations in metabolism or behavior can be shaped by environmental and genetic factors (e.g., behavior: Dingemanse et al. 2002; Bell et al. 2009; Bize et al. 2012; metabolism: Nespolo and Franco 2007; McKechnie 2008; Nilsson et al. 2009), it predicts that metabolism and behavior can exhibit phenotypic correlations among populations when responding (independently from each other) to co-varying selective forces. This prediction can be illustrated through the following simple hypothetical example. Because ambient temperature decreases with an increase in elevation, in endotherms, selection along an altitudinal gradient may favor individuals with greater metabolic rate and capacity to produce heat either through genetic variation or developmental plasticity (Gillooly et al. 2001; Lovegrove 2003; see also Goulet et al. 2017). Furthermore, because food resources may often become rarer and patchier with an increase in elevation, selection might also favor animals with greater exploratory activity at higher elevation (e.g., Kramer and Weary 1991). This hypothetical and assuredly simplistic example would predict the occurrence of a strong positive phenotypic covariation between metabolism and behaviors among populations of endotherms sampled at different elevations. Of note, when considering phenotypic plasticity only, similar arguments can be applied further over distinct ontogenetic periods (growth vs. adulthood) and time periods (e.g., winter vs. summer, breeding vs. non-breeding) rather than spatially distinct populations, asking for careful considerations of both spatial and time co-varying selective forces when studying phenotypic covariations between metabolism and behavior (e.g., for an example of the effect of breeding on trait covariation, see Lantová et al. 2011).

Secondly, because by definition behavioral traits are energy-demanding, selection could also lead to the phenotypic correlation of behavior and metabolism among individuals sampled within the same population (Biro and Stamps 2010; Réale et al. 2010). Accordingly, Careau and collaborators (Careau et al. 2008) have recently suggested two different models for their correlation, using basal metabolic rate (BMR) as a benchmark of metabolism. In birds and mammals, BMR is the lowest measure of metabolic rate of an adult individual that is at rest during its normal period of inactivity, post-absorptivity, and non-reproductivity, and within its thermoneutral zone (McNab 1997). Thus, BMR is often viewed as the minimum energy cost of living (White and Seymour 2004; Speakman et al. 2004). The "performance model" points out that BMR is determined by the size of organs responsible for acquiring and processing food. Because active or aggressive individuals need high energy throughput, they would be expected to have larger-thanaverage organs, and thus higher-than-average BMR which in turn should lead to a positive phenotypic correlation between behavior and metabolism among individuals from the same population. Alternatively, the "allocation model" points out that, because resources are often limited in nature, the amount of energy allocated to behavioral traits can come at the expense of the amount of energy devoted to body maintenance, which in turn should lead to a negative correlation between BMR and behavioral traits among individuals from the same population. A recent review by Mathot and Dingemanse (2015) shows that empirical results are predominantly supporting the performance model.

In the present study, our aim was to test for phenotypic covariation in resting metabolic rate (RMR) and exploration activity (EA) at both the among- and within-population levels in adult common voles (Microtus arvalis) captured from different populations at low ( $<520 \mathrm{~m}$ a.s.l.) and high elevations ( $>1400 \mathrm{~m}$ a.s.1.). EA is important for collecting information on food abundance and predation risk, and therefore, EA is expected to be both under strong environment-specific natural selection and plastic to be able to respond to changes in the environment. Furthermore, as highlighted above, elevation provides a natural gradient that encompasses several ecologically relevant factors (e.g., temperature, humidity, predation risk, vegetation, nutrients). We defined two main objectives.

Our first objective was to describe the variation and covariation in RMR and EA with changes in elevation. In this study, we did not measure variation of ecological factors in relation to elevation nor their effects on RMR and EA; we had no a priori 
prediction on how RMR and EA should vary with elevation. As discussed before, for example, we can expect voles from higher elevation to have higher RMR if ambient temperature decreases with elevation and higher RMR facilitates the maintenance of a high body temperature in the cold (Hayes 1989). Alternatively, we can expect voles from higher elevation to have lower RMR if food becomes less abundant at higher elevation and a lower metabolism helps sparing energy (Selman et al. 2001). Alternative predictions can also be made for EA. For instance, voles from higher elevation may have higher (or lower) EA if food becomes less abundant at higher elevation and high EA helps them to discover new food patches (or lower EA helps them sparing energy) (e.g., Sears et al. 2009). The sign of the covariation between RMR and EA would depend on the specific effect of elevation of both variables.

Our second objective was to test for covariation between RMR and EA at two different scales: among populations sampled at different elevations (i.e., among-population level) and among individuals sampled from the same population (i.e., within-population level). If RMR and EA showed similar responses along the elevation gradient, populations from the same elevation levels should show phenotypic convergence (Dennis et al. 2011). The covariation between RMR and EA along the elevation gradient would exist only at the amongpopulation level if it is due to independent co-varying selection pressures or phenotypic plasticity. However, if RMR and EA are genetically correlated (i.e., integrated, following Careau et al. 2008), then the covariation should also exist at the within-population level. The sign of the phenotypic correlation at the within-population level would indicate support for either the performance or the allocation model (Careau et al. 2008). Note that a phenotypic correlation at the within-population level may also be driven by correlated plasticity if for instance the two traits respond similarly to seasonal cues. Here, it is important to point that our phenotypic correlation is based on single, and not repeated, measures of RMR and EA per individual. Phenotypic correlations based on single measures need to be interpreted with care since they can be influenced by both among- and within-individual covariation, and thus, their value may misrepresent the true correlative value expected at the individual level when among- and within-individual variations are not identical (Niemelä and Dingemanse 2018).

\section{Materials and methods}

\section{General methods}

We used Longworth traps to capture 36 voles in four highelevation populations (1428 to $1695 \mathrm{~m}$ a.s.l.) and 43 voles in five low-elevation populations (439 to $513 \mathrm{~m}$ a.s.l.) in cantons Vaud and Valais, Switzerland (Table 1). Live trapping of voles from high-elevation populations took place in mid-October
2010 and of voles from low-elevation populations in earlyNovember 2010. Within $24 \mathrm{~h}$ after their capture in the field, voles were brought to the University of Lausanne (397 m a.s.1.), topically treated with the antiparasitic Ivomec(C) (Merial), and housed individually in polycarbonate cages $(42.5 \times 26.6 \times$ $18.5 \mathrm{~cm}$ ) in an animal facility room with a 14-h light: 10 -h dark cycle and a constant temperature of $22 \pm 1{ }^{\circ} \mathrm{C}$. Cages contained sawdust, hay, and a flower pot as cover. Water and food pellets were available ad libitum, and apples and endives were offered three times a week. Voles were acclimatized to the laboratory conditions during $30.8 \pm 0.9$ days (mean $\pm \mathrm{SE}$ ) before the measurement of their behavior.

\section{Behavioral measurements}

We measured EA using an open-field test (OFT) made of a $40 \times 40 \times 30-\mathrm{cm}$ squared Plexiglass ${ }^{\mathrm{TM}}$ box with its outside walls and floor covered with white paper and its ceiling with a dark sheet to stabilize the lightning conditions in the box. The testing room was adjacent to the animal facility room, and each vole was accustomed to handling by being carried under its flower pot (i.e., cover) for $1 \mathrm{~min} 2$ days prior to the test. Animals were denied food for the hour preceding the test to standardize their nutritional status, and in turn their motivation to explore their novel environment. Voles were tested between 08:20 and 16:40. At the beginning of the test, each vole was placed under its pot in one corner of the open field box, the door of the pot being closed, and it was given 3 min to settle down. Then, the door of the flower pot was opened, and three additional minutes were waited before removing the pot and starting the behavioral recording, even if the vole left the pot. Eighteen of the 79 voles tested left their pot before it was removed (nine voles from each elevation groups). The behavior of each vole was video-recorded during 3 min with a digital camera fixed on top of the open field arena. We cleaned the open field box with $70 \%$ ethanol before each behavioral test. To obtain an estimate of EA, we divided the floor of the open field arena into 36 squares of $44.4 \mathrm{~cm}^{2}$, and for each individual, we counted the number of lines crossed during the 3-mintrial. Videos were analyzed by two undergraduate students blindly with respect to elevation; the identity of the analyzer did not affect the results (effects of observer identity on EA measurements: ANOVA: $\left.F_{1,77}=0.26, P=0.61\right)$.

\section{Metabolic measurements}

At the end of the OFT, voles were transferred back to the animal room facility and individually housed in polycarbonate cages $(36.5 \times 20.7 \times 14.0 \mathrm{~cm})$ which can be sealed with a lid for metabolic measurement purpose performed 1 day after their behavioral measurement. We measured resting metabolic rate via indirect calorimetry $\left(\mathrm{O}_{2}\right.$ consumption $\left[\mathrm{V}_{\mathrm{O}_{2}}\right]$ and $\mathrm{CO}_{2}$ 
Table 1 Identity of common vole populations along with elevation of the study sites, coordinates, number of animals measured $(N)$, and means \pm SE body mass before the metabolic measurements, resting metabolic rate (RMR) divided by body mass, and exploratory behavior (EB) measured as the number of lines crossed during 3 min of exploration in an open-field test. Populations were divided in low- $(<513)$ and high $(>$ $1428 \mathrm{~m}$ )-elevation categories in the statistical analyses

\begin{tabular}{llllllll}
\hline Population & Elevation $(\mathrm{m})$ & Latitude & Longitude & $N$ & Body mass $(\mathrm{g})$ & $\mathrm{RMR}\left(\mathrm{mL} \mathrm{O}_{2} / \mathrm{h} / \mathrm{g}\right)$ & EA (nb. lines crossed/min) \\
\hline MOH & 1695 & 46.252 & 6.875 & 11 & $25.7 \pm 2.0$ & $2.13 \pm 0.24$ & $29.1 \pm 2.5$ \\
JOH & 1638 & 46.23 & 6.883 & 10 & $23.7 \pm 1.8$ & $2.22 \pm 0.25$ & $28.7 \pm 5.8$ \\
COH & 1443 & 46.405 & 7.111 & 7 & $24.3 \pm 3.1$ & $2.47 \pm 0.14$ & $28.1 \pm 9.8$ \\
LAH & 1428 & 46.463 & 6.957 & 8 & $22.9 \pm 2.4$ & $2.09 \pm 0.14$ & $44.2 \pm 4.3$ \\
CSL & 513 & 46.603 & 6.545 & 9 & $21.6 \pm 2.0$ & $1.75 \pm 0.17$ & $32.5 \pm 7.8$ \\
LSL & 491 & 46.651 & 6.506 & 7 & $21.7 \pm 1.3$ & $1.62 \pm 0.24$ & $25.9 \pm 5.5$ \\
BML & 465 & 46.551 & 6.524 & 10 & $22.1 \pm 1.4$ & $1.84 \pm 0.21$ & $26.6 \pm 7.4$ \\
ROL & 449 & 46.456 & 6.312 & 10 & $23.6 \pm 1.4$ & $1.71 \pm 0.18$ & $15.3 \pm 3.8$ \\
YVL & 439 & 46.77 & 6.573 & 7 & $26.4 \pm 2.1$ & $1.87 \pm 0.12$ & $26.5 \pm 7.2$ \\
\hline
\end{tabular}

production $\left.\left[V_{\mathrm{CO}_{2}}\right]\right)$ using a SM-MARS-4 open flow system allowing the measurements of 3 animals in parallel (Sable Systems International, Las Vegas, USA) as previously described in Lehto Hürlimann et al. (2014). The food was removed $1 \mathrm{~h}$ prior to the measurements that were performed between 08:00 and 16:00. The common vole forages and feeds throughout the day in regular episodes spaced by ca. 150 min (Gerkema et al. 1993), and thus, our measurements spanned both active and inactive periods. The cages were placed individually on an activity detector (Sable Systems MAD-1) in a versatile environmental test chamber (MLR$350 \mathrm{H}$; Sanyo, Japan). Measurements were conducted in the dark at a relative humidity of $50 \%$ and constant temperature of $30 \pm 1{ }^{\circ} \mathrm{C}$, which is within the thermoneutral zone for this species (Devevey et al. 2008). The air was pumped out of each cage with MFS-5 pumps with $1 \mathrm{~L} / \mathrm{min}$ rate to the Multiplexer (MUX) where the air sample $(500 \mathrm{~mL} / \mathrm{min})$ from only one cage at a time was pumped with subsampler (SS4) to the water vapor (RH-300)-, CO2 (CA-10)-, and O2-analyzers (FC-10) in this order. The raw data was analyzed using ExpeData software (Sable Systems International, Las Vegas, USA). One measuring cycle consisted of 2-min baseline recording (air from the climate chamber) in the beginning and at the end of the cycle to control for the baseline drift, and each cage being measured for 2-min period for $5 \times$. Sample was taken every second and an average of 45 last samples of every 2-min period was used as single reading. In total, three measuring cycles $(2$-min measuring periods per cage for $15 \times$ ) were recorded. The oxygen consumption $\left(\mathrm{mL} \mathrm{O}_{2} / \mathrm{h}\right)$ was calculated according to the equation

$\mathrm{VO}_{2}=\frac{\mathrm{FR} \times\left(\mathrm{F}_{\mathrm{i}} \mathrm{O}_{2}-\mathrm{F}_{\mathrm{e}} \mathrm{O}_{2}\right)-\mathrm{F}_{\mathrm{i}} \mathrm{O}_{2} \times\left(\mathrm{F}_{\mathrm{e}} \mathrm{CO}_{2}-\mathrm{F}_{\mathrm{i}} \mathrm{CO}_{2}\right)}{1-\mathrm{F}_{\mathrm{i}} \mathrm{O}_{2}}$

where $\mathrm{FR}=$ flow rate $(\mathrm{mL} / \mathrm{h}), \mathrm{F}_{\mathrm{i}} \mathrm{O}_{2}=$ fractional concentration of $\mathrm{O}_{2}$ in incurrent air (baseline), $\mathrm{F}_{\mathrm{e}} \mathrm{O}_{2}=$ fractional concentration of $\mathrm{O}_{2}$ in excurrent air, $\mathrm{F}_{\mathrm{i}} \mathrm{CO}_{2}=$ fractional concentration of $\mathrm{CO}_{2}$ in incurrent air, $\mathrm{F}_{\mathrm{e}} \mathrm{CO}_{2}=$ fractional concentration of $\mathrm{CO}_{2}$ in excurrent air. All values are corrected to standard temperature and pressure (STP) and corrected for water vapor pressure. As a measurement for RMR, we used the average of two lowest, consecutive readings when the voles were inactive (measured by the activity detector). If those criteria were not met, or the measurement failed because of technical reasons, the vole was measured again in 1 to 3 weeks and discarded if also the second trial did not meet the requirements. Measurements of four individuals (two from low elevation and two from high elevation) were discarded from the final analyses leading to final sample sizes of 34 and 41 voles from high- and low-elevation populations, respectively.

\section{Statistical analyses}

Firstly, we used univariate mixed models in "Ime4" R package (Bates et al. 2013) to investigate which factors best explained phenotypic variation in RMR $\left(\mathrm{mL} \mathrm{O}_{2} / \mathrm{h}\right)$ and EA (number of lines crossed during the OFT). In the models, we entered elevation (2 levels: low vs. high), sex (2 levels: male vs. female), body mass (continuous trait; log-transformed), number of acclimatization days in the laboratory (continuous trait), and time of the day at the start of the measure (continuous trait) as fixed factors and population identity as a random effect. The explanatory variables RMR and EA were, respectively, logtransformed and square root-transformed to normalize the distribution of the residuals. $P$ values of type III $F$ test for mixed models, with denominator degrees of freedom calculated using Satterthwaite's approximation, were computed using the function anova in "ImerTest" R package (Kuznetsova et al. 2013).

Secondly, we used a bivariate mixed model using "MCMCglmm" R package (Hadfield 2010) to investigate covariation between RMR and EA at the among- and within- 
population levels. To this end, we entered log-transformed RMR and square root-transformed EA as response variables with Gaussian distributions. To avoid over-parametrizing our bivariate model, we only entered as fixed effects the factors identified as significant in the univariate mixed models described above. We entered population identity as a random effect on both traits. Given the structure of the data, only one observation per individual on each trait, the residual variance in both traits and the residual covariance are interpreted as the phenotypic (co)variance between RMR and EA within populations. The response and explanatory variables were scaled before analysis (mean centered on 0 and SD reduced to 1) to facilitate the interpretation of the results (Schielzeth 2010). We estimated the covariance between RMR and EA generated by elevation using two complementary approaches. First, the covariance between BMR and EA due to their covariation with elevation can be estimated as Cov(RMR, $\mathrm{EA})=a \times b \times \operatorname{Var}($ elevation), where $a$ and $b$ are the regression coefficients of altitude on BMR and EA, respectively. Elevation was fitted as a 2-level factor and thus had a variance of 0.25 . Secondly, we inspected the changes in the variance and covariance matrix caused by the inclusion or exclusion of elevation in the bivariate model. We used the following priors for the residual $(V=\operatorname{diag}(2), \mathrm{nu}=0.002)$ and random effect matrices $(V=\operatorname{diag}(2) \times 0.002, \mathrm{nu}=1.002$, alpha.mu $=$ $\operatorname{rep}(0.2)$, alpha. $V=\operatorname{diag}(2))$. To compute the posterior distribution, the model was run over 200,000 iterations, with a burn-in of 30,000 and a thinning interval of 100 , to obtain an effective sample size between 1930 and 2185 with an autocorrelation level between retained iterations lower than 0.05 . Parameter convergence and appropriate mixing of the chain were assessed visually for each parameter. We also tested for an overall phenotypic correlation between RMR and EA within the 9 different populations by performing a metacorrelation using the "meta" R package (Schwarzer 2007) on the 9 correlation coefficients computed within each population.

\section{Results}

Males were heavier than female voles $\left(F_{1,76}=22.09\right.$, $P<0.001)$, and there was no difference in body masses between high- and low-elevation voles $\left(F_{1,76}=0.007, P=0.93\right)$ (mean $\pm \mathrm{SE}$ body mass in grams for males vs. females in highelevation populations, $26.1 \pm 1.4$ vs. $20.7 \pm 1.2$; males vs. females in low-elevation populations, $25.9 \pm 0.9$ vs. $20.5 \pm 0.8$ ).

Voles from high-elevation populations had significantly higher RMR than voles from low-elevation populations $\left(F_{1,69}=16.23, P<0.001\right.$; Fig. 1a). RMR increased with logtransformed body mass (estimate $\pm \mathrm{SE}=0.834 \pm 0.174$, $F_{1,69}=22.63, P<0.001$ ) (Fig. 2 ) and decreased with the number of acclimatization days in the laboratory (estimate $\pm \mathrm{SE}=$
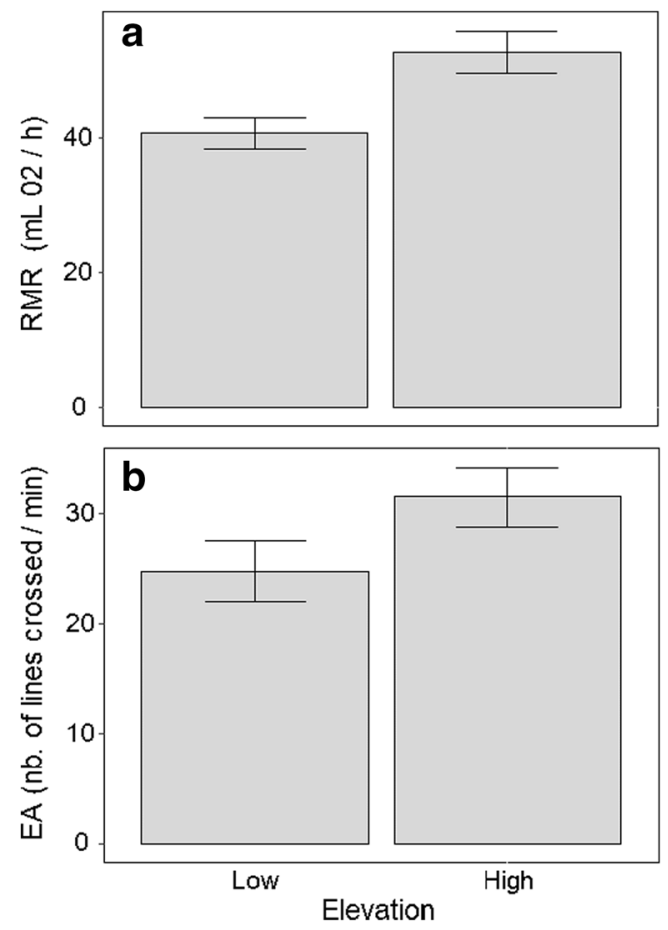

Fig. 1 Mean \pm SE resting metabolic rate (RMR) (a) and exploration activity (EA) (b) of common voles from low- $(<513 \mathrm{~m})$ and high (> $1428 \mathrm{~m}$ )-elevation populations

$\left.-0.014 \pm 0.006, F_{1,69}=5.60, P=0.021\right)$. Sex and time of the day when measured did not explained significant variation in RMR (sex: $F_{1,69}=0.17, P=0.69$; time of the day: $F_{1,69}=$ $0.08, P=0.77$ ).

Individual variations in EA was best explained by elevation and number of acclimatization days in the laboratory. Individuals from high elevation were more explorative than those from low elevation $\left(F_{1,73}=7.75, P=0.007\right.$; Fig. $\left.1 \mathrm{~b}\right)$.

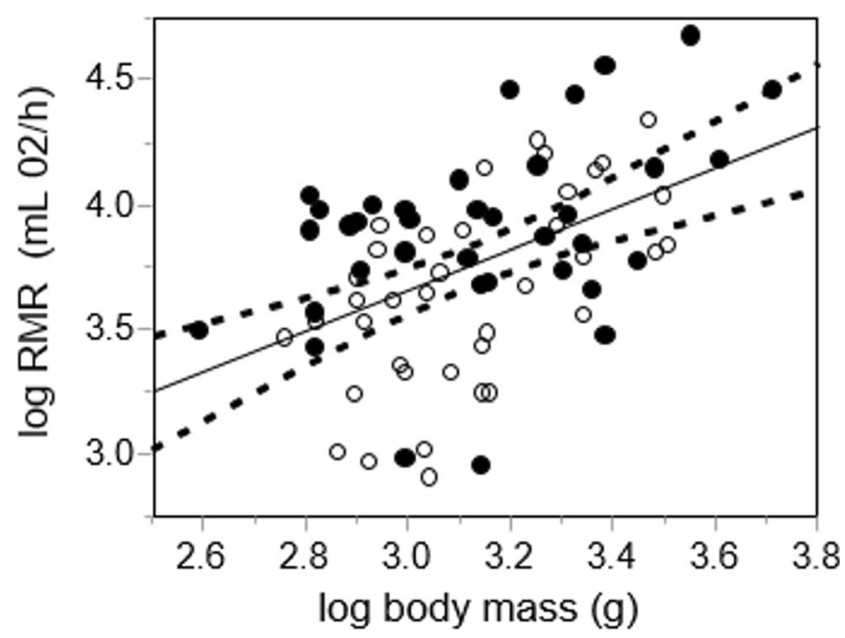

Fig. 2 Relationship between log-transformed resting metabolic rate (RMR) and log-transformed body mass in common voles issued from low- (<513 m; open circles) and high (>1428 m; closed circles)-elevation populations. The linear regression line (solid line) is presented with its $95 \%$ confidence interval (dashed lines) 
The level of exploration decreased with the number of days in the laboratory from their capture in the field to the behavioral test (estimate \pm SE: $-0.18 \pm 0.09 ; F_{1,73}=4.19, P=0.044$ ). Effects of sex, body mass, and time of the day when measured did not explained significant variation in EA (sex: $F_{1,73}=$ $1.58, P=0.21$; body mass: $F_{1,73}=0.07, P=0.79$; time of the day: $F_{1,73}=0.10, P=0.76$ ).

The use of a bivariate mixed model on scale values of RMR and EA values as response variables showed that elevation had a significant effect of similar magnitude on RMR (mean [95\% credible interval]: $-1.08[-1.58 ;-0.56])$ and EA $(-$ $1.28[-2.15 ;-0.36])$ (Table 2A), which has for consequence to generate phenotypic correlation in RMR and EA across populations of voles sampled at low versus high elevation of $0.28[0.064 ; 0.658]$ (Fig. 3). Inspection of the variance components of models with vs. without elevation in the explanatory variables (Table $2 \mathrm{~A}$ vs. $2 \mathrm{~B}$ ) provided similar findings. Indeed, when elevation was included in the explanatory variables, there was almost no variance left to be explained at the among-population level in both RMR $\left(0.010\left[1.02 \times 10^{-9}\right.\right.$; $0.046])$ and EA $\left(0.017\left[5.68 \times 10^{-10}, 0.079\right]\right)$ and no covariance between them $(-0.001[-0.027 ; 0.023])$ (Table 2A). In contrast, when elevation was removed from the explanatory variables, it was possible to detect at the population level some variance in both RMR $\left(0.085\left[1.52 \times 10^{-10} ; 0.342\right]\right)$ and EA

Table 2 Estimates of fixed effects and variance components for resting metabolic rate (RMR) and exploration activity (EA) in wild-captured common voles, obtained from bivariate mixed models. Panel (A) reports the estimates of fixed effects and variance components with elevation included in the explanatory variables, and panel (B) reports the variance components after removing elevation from the explanatory variables. $\left(0.087\left[3.26 \times 10^{-8} ; 0.383\right]\right)$ and a positive (though nonsignificant $)$ covariance between them $(0.051[-0.068$, 0.299]) (Table 2B). Finally, although both models showed significant phenotypic variance within populations (estimated as residual variance in the model) in RMR (model with vs. without elevation: 0.639 [0.445; 0.853$]$ vs. 0.736 [0.494; $0.994])$ and EA $(0.952[0.655,1.305]$ vs. $1.021[0.709$, $1.384]$ ), it provides no evidence of phenotypic covariation $(0.005[-0.162 ; 0.195]$ vs. $0.077[-0.142 ; 0.292])$ (Table 2). Examination of the phenotypic correlation coefficients between RMR and EA computed within each of the nine populations showed no consistent pattern. Correlation coefficients ranged from strongly negative to positive values (Fig. 4), which led to a non-significant overall phenotypic correlation of $r=0.14$ [-0.14; 0.40] (mean [95\% CI]; raw data are shown on Fig. $1 \mathrm{~S}$ in the Supplementary Material).

\section{Discussion}

Our study shows that voles from high-elevation populations had higher resting metabolic rate (RMR) and higher exploration activity (EA) compared with their counterparts from lowelevation populations. Furthermore, the bivariate analyses between RMR and EA highlight that distinct populations

Variation in response and explanatory variables were scaled before analysis to facilitate the interpretation of the estimates (Schielzeth 2010). Given the structure of the data, the residual variance and covariance are interpreted as the phenotypic (co)variance within populations. The table gives the mean posterior distribution and its $95 \%$ credible interval (CI)

\begin{tabular}{|c|c|c|c|c|c|c|c|}
\hline & & \multicolumn{3}{|c|}{ Resting metabolic rate (RMR) } & \multicolumn{3}{|c|}{ Exploratory behavior (EB) } \\
\hline & & Estimate & $95 \% \mathrm{CI}$ & & Estimate & $95 \% \mathrm{CI}$ & \\
\hline \multirow[t]{11}{*}{ (A) } & Fixed effects & & & & & & \\
\hline & Elevation (low) & -1.075 & -1.577 & -0.561 & -1.278 & -2.149 & -0.358 \\
\hline & Days in the lab & -0.314 & -0.567 & -0.046 & -0.497 & -0.950 & -0.094 \\
\hline & Log-weight (g) & 0.528 & 0.355 & 0.707 & & & \\
\hline & Intercept & 0.582 & 0.247 & 0.932 & -0.499 & -0.973 & -0.103 \\
\hline & Random effects & & & & & & \\
\hline & $\operatorname{Var}_{\text {Population }}$ & 0.010 & $1.02 \times 10^{-9}$ & 0.046 & 0.017 & $5.68 \times 10^{-10}$ & 0.079 \\
\hline & $\operatorname{Var}_{\text {Residual }}$ & 0.639 & 0.445 & 0.853 & 0.952 & 0.655 & 1.305 \\
\hline & & & Estimate & $95 \% \mathrm{CI}$ & & & \\
\hline & & Covar $_{\text {Population }}$ & -0.001 & -0.027 & 0.023 & & \\
\hline & & Covar ${ }_{\text {Residual }}$ & 0.005 & -0.162 & 0.195 & & \\
\hline \multirow[t]{6}{*}{ (B) } & Random effects & & & & & & \\
\hline & $\operatorname{Var}_{\text {Population }}$ & 0.085 & $1.52 \times 10^{-10}$ & 0.343 & 0.087 & $3.68 \times 10^{-8}$ & 0.383 \\
\hline & $\operatorname{Var}_{\text {Residual }}$ & 0.736 & 0.494 & 0.994 & 1.020 & 0.709 & 1.384 \\
\hline & & & Estimate & $95 \% \mathrm{CI}$ & & & \\
\hline & & Covar $_{\text {Population }}$ & 0.051 & -0.068 & 0.299 & & \\
\hline & & Covar $_{\text {Residual }}$ & 0.077 & -0.142 & 0.292 & & \\
\hline
\end{tabular}




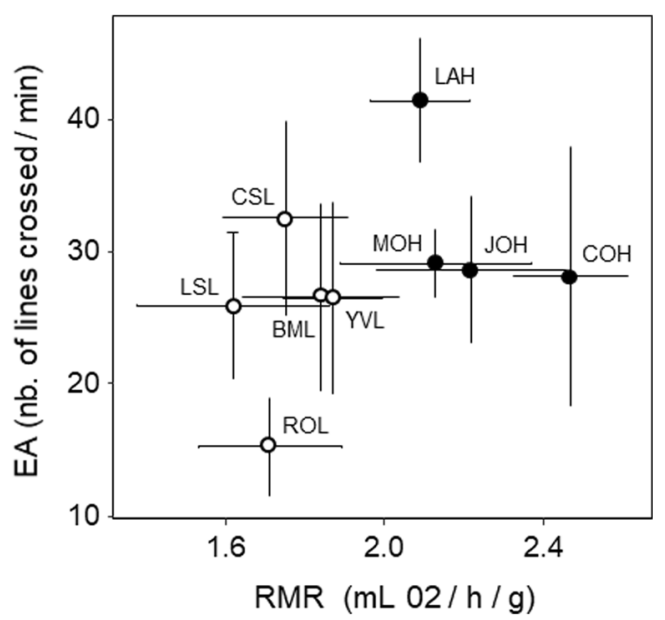

Fig. 3 Covariation between resting metabolic rate (RMR) and exploration activity (EA) of common voles issued from low- $(<513 \mathrm{~m})$ and high (>1428 m)-elevation populations. The identity of each population is written next to its corresponding mean \pm SE population value; information on each population is reported in Table 1

exposed to a common selective force, here an elevation gradient, lead to a phenotypic correlation between RMR and EA at the among-population level. However, we found no evidence of a phenotypic correlation between RMR and EA among individuals from a same population, and thus no evidence of their phenotypic integration. This last result needs nonetheless to be interpreted with care since our phenotypic correlation relies on single measures per individual of RMR and EA, and this approach does not allow to tease apart the contribution of among- and within-individual variations at generating correlation between labile traits (Niemelä and Dingemanse 2018; see also the discussion below). Overall, our results suggest that the environmental correlation between RMR and EA is due to phenotypic plasticity and/or adaptation to co-varying selection pressures.

\section{Altitudinal variation in RMR and EA}

The clear differences in RMR and EA observed between voles from low- and high-elevation populations are opening two major questions. Firstly, are those differences fostered by genetic effects and/or phenotypic plasticity, and secondly what is/are the natural selective force(s) driving those differences. With our design, we cannot say if the observed differences in RMR and EA were driven by independent genetic adaptations to elevation due to co-varying selection pressures and/or by phenotypic adaptations of similar genotypes exposed to lowand high-elevation environmental conditions (i.e., phenotypic plasticity). Our results suggest nonetheless that both processes might be important. Pilot results on a small subsample of voles from this study that were measured twice during their time in captivity showed that RMR and EA were significantly repeatable $(r=0.58$ and $n=23$ individuals for RMR, and $r=0.61$ and $n=17$ for EA, see Supplementary Material for details). Because repeatability establishes the upper limit for heritability (Lessells and Boag 1987; Falconer and Mackay 1996; Ronning et al. 2005; but see Dohm 2002), our results highlight plausible additive genetic effects on variations in RMR and EA in the common vole. Our findings are also pointing toward plastic responses in RMR and EA. Both traits were decreasing with the time spent in the laboratory, which indicates that voles were acclimatizing to their new laboratory conditions. When brought from the field to the laboratory, obvious major changes in their environment were higher ambient temperatures $\left(22^{\circ}\right.$ in the laboratory vs. $8.9^{\circ} \mathrm{C}$ or $2.5^{\circ} \mathrm{C}$ for the elevations $455 \mathrm{~m}$ or $1974 \mathrm{~m}$, respectively, based on mean temperatures of October-November for locations Pully and Le Moléson in years 1981-2010; Federal office for meteorology and climatology MeteoSwiss, www.meteoswiss.ch), ad libitum access to food and water, no predators, and smaller living space. Common garden experiments where animals

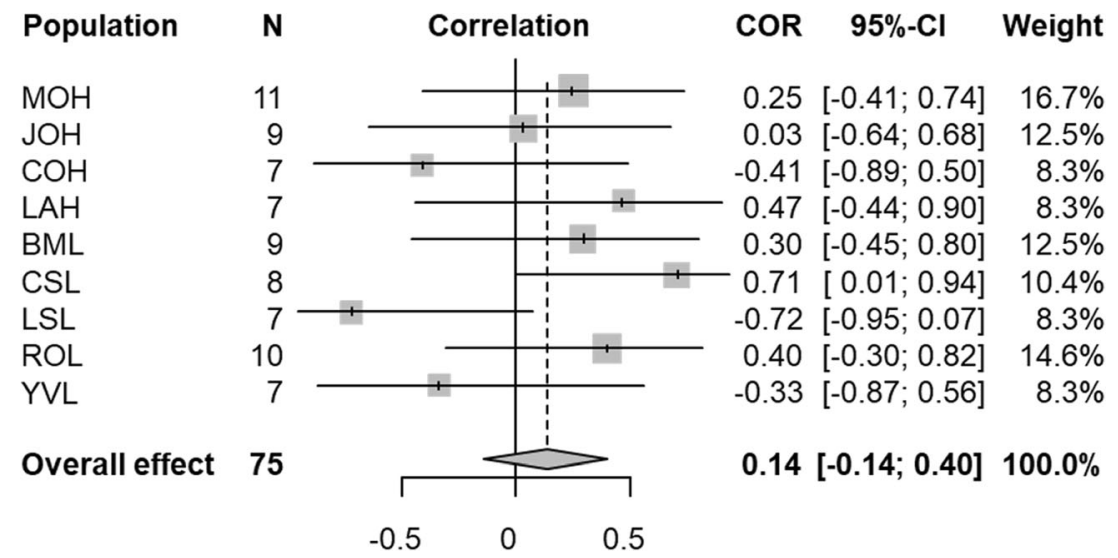

Fig. 4 Results of a meta-correlation of the within-population phenotypic correlations between resting metabolic rate (RMR) and exploration activity (EA) of common voles issued from five low $(<513 \mathrm{~m})$-elevation populations (BML, CSL, LSL, ROL, YVL) and four high (>1428 m)-

elevation populations ( $\mathrm{MOH}, \mathrm{JOH}, \mathrm{COH}, \mathrm{LAH})$. Correlation coefficients (COR) are reported together with their $95 \%$ confidence intervals $(95 \%$ $\mathrm{CI})$ and sample sizes $(N)$ 
from different elevations are housed, for instance, at different ambient temperatures are now required to address the importance of genetics and adaptive plasticity in shaping the RMR and EA of adult common voles (for an example of such approach, see Tsuchiya et al. 2012).

Many ecologically relevant factors vary along the elevation (just as from the field to the laboratory) and can affect RMR and EA. One of the best studied factors is the ambient temperature, with rodents issued from higher elevations, but also from cooler environments, showing higher BMR or RMR (Hayes 1989; Lovegrove 2003; Russell and Chappell 2007; but see Hammond et al. 1999; Rezende et al. 2004). Accordingly, we found that common voles from highelevation populations had higher RMR than those from lowelevation populations, and that RMR declined when acclimatized to laboratory conditions $\left(22^{\circ} \mathrm{C}\right)$. Those findings are consistent with the idea that the altitudinal gradient can shape RMR through greater need for endotherms to produce heat at higher elevations/cooler temperatures (Rodríguez-Serrano and Bozinovic 2009). Interestingly, because greater energetic for heat production can lead to greater food intake, as observed in rodents exposed to cold or acclimatized to high elevations (e.g., Selman et al. 2008; Hammond et al. 1999), the same ecological factors might also favor greater activity and exploration activity in the quest for food (Sears et al. 2006, 2009). Although we do not have information about food abundance and predation risk in our study populations, they are also potential factors to vary along an elevation gradient. In higher elevations, food resources might be scarcer, which could lead to higher levels of EA (Kramer and Weary 1991). As exploration increases the susceptibility to predators, between population differences in predation risk could also select for different optimal levels of EA (Herczeg et al. 2009; Bergeron et al. 2013).

\section{Phenotypic correlation among- and within-populations between RMR and EA}

Because natural selection is often impacting more than one trait at a time, one first important consequence is that phenotypic convergence of alternative, isolated traits can lead to their phenotypic correlation among populations. A second important consequence of selection for trait combinations is that this might also lead to the evolution of a functional integration among traits at the level of the individual, and ultimately to the existence of genetic correlations between these traits at the level of the population (Duckworth and Badyaev 2007; Versteegh et al. 2012). In agreement with the idea that phenotypic convergence of alternative traits in response to natural selection can lead to their phenotypic correlation among populations, the strong positive effects of elevation on RMA and EA led to positive correlation among them of 0.28 [0.064; 0.658$]$. This result was further supported by changes in the covariance matrix of the bivariate models where a positive phenotypic correlation, though non-significant, between RMR and EA was only becoming apparent when elevation was removed from the models. The lack of a significant covariance at the population level in the second approach, despite strong effects of elevation on both traits, is most likely explained by low statistical power coming from the fact that only nine populations from two elevations were sampled. Our results in voles are in line with recent findings in western stutter-trilling cricket (Gryllus integer) suggesting that correlations between physiological, behavioral, and life history traits could have occurred due to environmental factors rather than due to genetic constraints (Niemelä et al. 2013; see also Krams et al. 2017).

It has also been suggested that selection on energy acquisition or allocation can lead to either positive or negative correlations between RMR and EA at the individual level (Careau et al. 2008; Mathot and Dingemanse 2015). Results from the bivariate models and the meta-correlation provided, however, no evidence of consistent phenotypic correlations within-populations between RMR and EA: the more explorative individuals from a population had neither a higher RMR nor a lower RMR than the less explorative ones. Our results are nonetheless based on single measures per individual, and work using repeated measures of RMR and EA from the same individuals (Boulton et al. 2015), repeated measures over multiple generations from the same families (i.e., pedigree approach; Careau et al. 2011), or experimental selection on RMR or EA (Vaanholt et al. 2007; Gebczynski and Konarzewski 2009; Careau et al. 2010) is required to adequately test integration between RMR and EA at the individual level. Such studies remain rare and are currently providing contrasting results. For instance, the use of long-term pedigree approach in wild-derived deer mice (Peromyscus maniculatus) showed a positive genetic correlation, but without a phenotypic correlation, between RMR and EA (Careau et al. 2011). Artificial selection experiments on laboratory mice showed that selection for high BMR led to higher activity (Gebczynski and Konarzewski 2009) whereas selection for higher activity led to lower RMR (Vaanholt et al. 2007). In contrast, dog breeds selected for high aggressiveness have higher energetic needs (Careau et al. 2010).

\section{Conclusion}

Links between physiological, behavioral, and life-history traits are gaining increasing interest among evolutionary biologist as they are central for understanding evolutionary potential and limitations of populations and species (Careau et al. 2008; Biro and Stamps 2010; Ketterson et al. 2009; Réale et al. 2010; Careau and Garland 2012; Mathot and Dingemanse 2015; Sih et al. 2015). An important step is to understand the relative importance of genetics and environment factors in shaping complex (multivariate) phenotypes (Swallow and Garland 2005). In our study, we could show, by comparing among- and within- 
population correlations, that RMR and EA can be linked by independent responses to co-varying selection environmental forces. Future studies on correlations between complex phenotypes should take into consideration the effect of environmental factors shaping the traits alone and correlations between them.

Acknowledgments We are grateful to Raphaelle Flint and Jéremie Projer for their help in the video analyses, and to Laelia Maumary, Jézaelle Rufener and Jason Buser for their help in the animal room. Comments provided by two anonymous referees greatly helped to improve our manuscript.

Authors' contributions MLH and PB designed the experiment and collected the data. MLH, JGAM, and PB analyzed the data and wrote the manuscript.

Funding source This research was support by a grant to PB (no. 31003A 124988) from the Swiss National Science Foundation.

Data availability The datasets generated and/or analyzed during the current study are available from the corresponding author on reasonable request.

\section{Compliance with ethical standards}

Conflict of interest The authors declare that they have no conflict of interest

Ethical approval All procedures followed the ASAB/ABS guidelines for the ethical treatment of animals in behavioral research and teaching and all applicable international, national, and/or institutional guidelines for the care and use of animals were followed. Wild common voles were live-trapped in the field under the legal authorization of the wildlife services of the canton Vaud (license no. 1021), and they were brought to the laboratory for measuring their metabolism and behavior under the legal authorization of the veterinary services of the canton Vaud (licenses nos. 2247.0 and 2247.1). Ethical approval for involving animals in this study was received through the application procedure for animal experiment to the veterinary services of the canton Vaud. At the end of this study, animals have been kept in the laboratory and used in a long-term breeding experiment.

Open Access This article is distributed under the terms of the Creative Commons Attribution 4.0 International License (http:// creativecommons.org/licenses/by/4.0/), which permits unrestricted use, distribution, and reproduction in any medium, provided you give appropriate credit to the original author(s) and the source, provide a link to the Creative Commons license, and indicate if changes were made.

\section{References}

Bates D, Maechler M, Bolker B, Walker S (2013) lme4: linear mixedeffects models using Eigen and S4 https://cran.r-project.org/web/ packages/lme4/index.html

Bell AM, Hankison SJ, Laskowski KL (2009) The repeatability of behaviour: a meta-analysis. Anim Behav 77:771-783

Bergeron P, Montiglio PO, Réale D, Humphries MM, Gimenez O, Garant D (2013) Disruptive viability selection on adult exploratory behaviour in eastern chipmunks. J Evol Biol 26:766-774

Biro PA, Stamps JA (2010) Do consistent individual differences in metabolic rate promote consistent individual differences in behavior? Trends Ecol Evol 25:653-659
Bize P, Diaz C, Lindström J (2012) Experimental evidence that adult antipredator behaviour is heritable and not influenced by behavioural copying in a wild bird. Proc R Soc Lond B 279:1380-1388

Boulton K, Couto E, Grimmer AJ, Earley RL, Canario AVM, Wilson AJ, Walling CA (2015) How integrated are behavioral and endocrine stress response traits? A repeated measures approach to testing the stress-coping style model. Ecol Evol 5:618-633

Careau V, Garland T (2012) Performance, personality, and energetics: correlation, causation, and mechanism. Physiol Biochem Zool 85: $543-571$

Careau V, Thomas D, Humphries MM, Réale D (2008) Energy metabolism and animal personality. Oikos 117:641-653

Careau V, Réale D, Humphries MM, Thomas DW (2010) The pace of life under artificial selection: personality, energy expenditure, and longevity are correlated in domestic dogs. Am Nat 175:753-758

Careau V, Thomas D, Pelletier F, Turki L, Landry F, Garant D, Réale D (2011) Genetic correlation between resting metabolic rate and exploratory behaviour in deer mice (Peromyscus maniculatus). J Evol Biol 24:2153-2163

Christin P-A, Weinreich DM, Besnard G (2010) Causes and evolutionary significance of genetic convergence. Trends Genet 26:400-405

Conover DO, Schultz ET (1995) Phenotypic similarity and the evolutionary significance of countergradient variation. Trends Ecol Evol 10: 248-252

Dennis SR, Carter MJ, Hentley WT, Beckerman AP (2011) Phenotypic convergence along a gradient of predation risk. Proc R Soc Lond B 278:1687-1696

Devevey G, Niculita-Hirzel H, Biollaz F, Yvon C, Chapuisat M, Christe P (2008) Developmental, metabolic and immunological costs of flea infestation in the common vole. Funct Ecol 22:1091-1098

Dingemanse NJ, Both C, Drent PJ, van Oers K, van Noordwijk AJ (2002) Repeatability and heritability of exploratory behaviour in great tits from the wild. Anim Behav 64:929-938

Dohm MR (2002) Repeatability estimates do not always set an upper limit to heritability. Funct Ecol 16:273-280

Duckworth RA, Badyaev AV (2007) Coupling of dispersal and aggression facilitates the rapid range expansion of a passerine bird. Proc Natl Acad Sci U S A 104:15017-15022

Falconer DS, Mackay TFC (1996) Introduction to quantitative genetics, 4th edn. Longman, Harlow

Gebczynski AK, Konarzewski M (2009) Locomotor activity of mice divergently selected for basal metabolic rate: a test of hypotheses on the evolution of endothermy. J Evol Biol 22:1212-1220

Gerkema MP, Daan S, Wilbrink M, Hop MW, van der Leest F (1993) Phase control of ultradian feeding rhythms in the common vole (Microtus arvalis): the roles of light and the circadian system. J Biol Rhythm 8:151-171

Gillooly JF, Brown JH, West GB, Savage VM, Charnov EL (2001) Effects of size and temperature on metabolic rate. Science 293: 2248-2251

Goulet CT, Thompson MB, Michelangeli M, Wong BBM, Chapple DG (2017) Thermal physiology: a new dimension of the pace-of-life syndrome. J Anim Ecol 86:1269-1280

Hadfield JD (2010) MCMC methods for multi-response generalized linear mixed models: the MCMCglmm R package. J Stat Softw 33:1-22

Hague MTJ, Feldman CR, Brodie ED Jr, Brodie ED III (2017) Convergent adaptation to dangerous prey proceeds through the same first-step mutation in the garter snake Thamnophis sirtalis. Evolution 71:1504-1518

Hammond KA, Roth J, Janes DN, Dohm MR (1999) Morphological and physiological responses to altitude in deer mice maniculatus. Physiol Biochem Zool 72:613-622

Hayes J (1989) Altitudinal and seasonal effects on aerobic metabolism of deer mice. J Comp Physiol B:159453-159459 
Herczeg G, Gonda A, Merilä J (2009) Predation mediated population divergence in complex behaviour of nine-spined stickleback (Pungitius pungitius). J Evol Biol 22:544-552

Holtmann B, Lagisz M, Nakagawa S (2017) Metabolic rates, and not hormone levels, are a likely mediator of between-individual differences in behaviour: a meta-analysis. Funct Ecol 31:685-696

Ketterson ED, Atwell JW, McGlothlin JW (2009) Phenotypic integration and independence: hormones, performance, and response to environmental change. Integr Comp Biol 49:365-379

Kramer DL, Weary DM (1991) Exploration versus exploitation: a field study of time allocation to environmental tracking by foraging chipmunks. Anim Behav 41:443-449

Krams IA, Niemelä PT, Trakimas G, Krams R, Burghardt GM, Krama T, Kuusik A, Mänd M, Rantala MJ, Mänd R, Kekäläinen J, Sirkka I, Luoto S, Kortet R (2017) Metabolic rate associates with, but does not generate covariation between, behaviours in western stuttertrilling crickets, Gryllus integer. Proc R Soc B 284:20162481

Kuznetsova A, Brockhoff P, Christensen R (2013) lmerTest: tests for random and fixed effects for linear mixed effect models (lmer objects of lme4 package). https://cran.r-project.org/web/packages/lmerTest/

Lantová P, Zub K, Koskela E, Šíchová K, Borowski Z (2011) Is there a linkage between metabolism and personality in small mammals? The root vole (Microtus oeconomus) example. Physiol Behav 104:378-383

Lehto Hürlimann M, Stier A, Scholly O, Criscuolo F, Bize P (2014) Short- and long-term effects of litter size manipulation in a small wild-derived rodent. Biol Lett 10:20131096

Lessells CM, Boag PT (1987) Unrepeatable repeatabilities: a common mistake. Auk 104:116-121

Lovegrove BG (2003) The influence of climate on the basal metabolic rate of small mammals: a slow-fast metabolic continuum. J Comp Physiol B 173:87-112

Mathot KJ, Dingemanse NJ (2015) Energetics and behavior: unrequited needs and new directions. Trends Ecol Evol 30:199-206

McKechnie A (2008) Phenotypic flexibility in basal metabolic rate and the changing view of avian physiological diversity: a review. J Comp Physiol B 178:235-247

McNab BK (1997) On the utility of uniformity in the definition of basal rate of metabolism. Physiol Zool 70:718-720

Nespolo RF, Franco M (2007) Whole-animal metabolic rate is a repeatable trait: a meta-analysis. J Exp Biol 210:2000-2005

Niemelä PT, Dingemanse NJ (2018) On the usage of single measurements in behavioural ecology research on individual differences. Anim Behav 145:99-105

Niemelä PT, Dingemanse NJ, Alioravainen N, Vainikka A, Kortet R (2013) Personality pace-of-life hypothesis: testing genetic associations among personality and life history. Behav Ecol 24:935-941

Nilsson JÅ, ÅKesson M, Nilsson JF (2009) Heritability of resting metabolic rate in a wild population of blue tits. J Evol Biol 22:1867-1874

Oke KB, Bukhari M, Kaeuffer R, Rolshausen G, Räsänen K, Bolnick DI, Peichel CL, Hendry AP (2016) Does plasticity enhance or dampen phenotypic parallelism? A test with three lake-stream stickleback pairs. J Evol Biol 29:126-143

Piersma T, van Gils JA (2011) The flexible phenotype: a body-centred integration of ecology, physiology, and behaviour. Oxford University Press, Oxford

Réale D, Garant D, Humphries MM, Bergeron P, Careau V, Montiglio PO (2010) Personality and the emergence of the pace-of-life syndrome concept at the population level. Philos Trans R Soc Lond B Biol Sci 365:4051-4063
Rezende EL, Bozinovic F, Garland T (2004) Climatic adaptation and the evolution of basal and maximum rates of metabolism in rodents. Evolution 58:1361-1374

Rodríguez-Serrano E, Bozinovic F (2009) Interplay between global patterns of environmental temperature and variation in nonshivering thermogenesis of rodent species across large spatial scales. Glob Chang Biol 15:2116-2122

Ronning B, Moe B, Bech C (2005) Long-term repeatability makes basal metabolic rate a likely heritable trait in the zebra finch Taeniopygia guttata. J Exp Biol 208:4663-4669

Russell GA, Chappell MA (2007) Is BMR repeatable in deer mice? Organ mass correlates and the effects of cold acclimation and natal altitude. J Comp Physiol B 177:75-87

Schielzeth H (2010) Simple means to improve the interpretability of regression coefficients. Methods Ecol Evol 1:103-113

Schwarzer G (2007) Meta: an R package for meta-analysis. R News 7: $40-45$

Sears MW, Hayes JP, O'Connor CS, Geluso K, Sedinger JS (2006) Individual variation in thermogenic capacity affects above-ground activity of high-altitude deer mice. Funct Ecol 20:97-104

Sears MW, Hayes JP, Banta MR, McCormick D (2009) Out in the cold: physiological capacity influences behaviour in deer mice. Funct Ecol 23:774-783

Selman C, Lumsden S, Bunger L, Hill WG, Speakman JR (2001) Resting metabolic rate and morphology in mice (Mus musculus) selected for high and low food intake. J Exp Biol 204:777-784

Selman C, McLaren JS, Collins AR, Duthie GG, Speakman JR (2008) The impact of experimentally elevated energy expenditure on oxidative stress and lifespan in the short-tailed field vole Microtus agrestis. Proc R Soc Lond B 275:1907-1916

Sih A, Mathot KJ, Moirón M, Montiglio P-O, Wolf M, Dingemanse NJ (2015) Animal personality and state-behaviour feedbacks: a review and guide for empiricists. Trends Ecol Evol 30:50-60

Speakman JR, Król E, Johnson MS (2004) The functional significance of individual variation in basal metabolic rate. Physiol Biochem Zool 77:900-915

Swallow JG, Garland T (2005) Selection experiments as a tool in evolutionary and comparative physiology: insights into complex traitsan introduction to the symposium. Integr Comp Biol 45:387-390

Tsuchiya Y, Takami Y, Okuzaki Y, Sota T (2012) Genetic differences and phenotypic plasticity in body size between high- and low-altitude populations of the ground beetle Carabus tosanus. J Evol Biol 25: 1835-1842

Vaanholt LM, de Jong B, Garland T, Daan S, Visser GH (2007) Behavioural and physiological responses to increased foraging effort in male mice. J Exp Biol 210:2013-2024

Versteegh MA, Schwabl I, Jaquier S, Tieleman BI (2012) Do immunological, endocrine and metabolic traits fall on a single Pace-of-Life axis? Covariation and constraints among physiological systems. J Evol Biol 25:1864-1876

White CR, Seymour RS (2004) Does basal metabolic rate contain a useful signal? Mammalian BMR allometry and correlations with a selection of physiological, ecological, and life-history variables. Physiol Biochem Zool 77:929-941

Publisher's note Springer Nature remains neutral with regard to jurisdictional claims in published maps and institutional affiliations. 